\title{
МОТИВАЦИЯ ВЫБОРА ПРОФЕССИИ ПРЕДСТАВИТЕЛЯМИ РАЗНЫХ ПОКОЛЕНИЙ В РОССИИ (НА ПРИМЕРЕ ПРЕДСТАВИТЕЛЕЙ СФЕРЫ ОБРАЗОВАНИЯ)
}

\section{MOTIVATION FOR CHOOSING A \\ PROFESSION BY REPRESENTATIVES OF DIFFERENT GENERATIONS IN RUSSIA (ON THE EXAMPLE OF REPRESENTATIVES OF THE EDUCATION SECTOR)}

\section{Usoltseva}

Summary: The article analyzes the features of motivation when choosing a profession by representatives of four generations of Russia. This is a modern study of the motives for choosing a profession in different conditions of professional self-determination in the country during 19652015. The results of the research presented in the article allow us to see the similarity and difference of internal and external, social and personal motives for choosing a profession, as well as trends in changes in the imposed choice of young men in different time periods.

Keywords: generation, choice of profession, motives for choosing a profession, factors for choosing a profession.

\author{
Усольцева Виктория Владимировна \\ К.nсх.н., дочент, Омский государственный \\ педагогический университет, г. Омск \\ Vikitory@yandex.ru
}

Аннотация: В статье анализируются особенности мотивации при выборе профессии представителями четырех поколений России. Это современное исследование мотивов выбора профессии в разных условиях профессионального самоопределения в стране на протяжении 1965-2015гг. Результаты исследования, представленные в статье, позволяют увидеть схожесть и различие внутренних и внешних, социальных и личностных мотивов выбора профессии, а также тенденции изменения навязанного выбора юношам в разные временные периоды.

Ключевые слова: поколение, выбор профессии, мотивы выбора профессии, факторы выбора профессии.

В большинстве случаев их в психологии разделяют на внешние (появляющиеся и воздействующие со стороны) и внутренние (вытекающие из собственных побуждений и целей) [1]. А.И. Зелинченко и А.Г. Шмелёв к внешним мотивам относят: давление, притяжение-отталкивание, бессодержательную мотивировку и социально-экономические факторы. [5]. Говоря о внутренних факторах, влияющих на мотивацию выбора профессии, можно выделить факторы социального и индивидуального характера. К внутренним индивидуальным факторам можно отнести явления, связанные с индивидуально-психологическими особенностями старшеклассника. Внутренними социальными факторами являются мотивы, побуждающие человека работать ради общества, которые являются отчасти альтруистическими. Примером подобных мотивов может служить желание помочь обществу, стране в целом или какой-либо её части.

С точки зрения прикладной психологии, практики психологической диагностики профессионального выбора, необходимо рассмотреть типологию мотивов выбора профессии, предложенную Кибиревым А.А. Основной принцип классификации А.А. Кибирева - формирование навязанной мотивации. Это выбор профессии, при котором человек не осознаёт собственных желаний и стремлений, а ориентируется лишь на факторы, кото- 
рые влияют на него. Такими факторами влияния могут являться наследственность, родственники, близкие друзья, одноклассники или же средства массовой информации (интернет, телевидение) [2].

Кибиревым А.А. на основе работ Тихомирова А.В. были выделены следующие мотивы: родительский сценарий, династический выбор, родительское завещание, консультационный выбор, компенсаторный выбор, стадный выбор, социально-инфраструктурный выбор, ситуационно-прагматический выбор, предметный выбор, инфантильный выбор, антипрофессиия. Первые три навязанных мотива выбора профессии представляют собой навязывание данного выбора со стороны семьи и близких родственников. Четвёртым навязанным видом мотивации - является «консультативный выбор» - выбор под влиянием специалиста по профориентации. Компенсаторный выбор основывается на желании человека выбрать профессию, благодаря которой он сможет компенсировать свои недостатки. Стадный выбор - вместе с друзьями [3]. Социально-инфраструктурный навязанный мотив подразумевает под собой навязывание со стороны страны и региона. Социально-экономическая обстановка в различных регионах страны имеет различные особенности, которые вызывают необходимость в наличии определённых профессиональных кадров. Ситуационнопрагматичный мотив выбора включает в себя желание и стремление найти работу, которая - в первую очередь - будет приносить много денег и давать особые привилегии [5]. Мотив предметного выбора складывается исходя из предпочитаемых учебных дисциплин, которые представляют больший интерес или проще усваиваются. Инфантильный выбор - проявление нежелания человека принимать на себя в полной мере ответственность за свой выбор. Антипрофессия - это мотив, который побуждает не к стремлению к какой-то профессии, а к отторжению от других. Представленные типы мотивов выбора профессии позволяют определить основные цели их исследования у разных поколений.

Актуальность исследования заключается в определении приоритетов мотивации профессионального самоопределения у представителей разных поколений нашей страны. Поколение - это социальное понятие, предназначенное для объединения людей в группу по критерию времени, в котором данная группа людей проживала. Мирошкиной М.Р. представлена периодизация поколений с точки зрения Российского государства [4]. В данном подходе главная роль уделяется историческим событиям, в контексте которых жили данные поколения. Поколение революции - 1903-1924 гг., поколение победителей, поколение оттепели - 1923-1940 гг., первое послевоенное поколение, поколение холодной войны - 1941-1964 гг., последнее послесоветское поколение, поколение перестройки - 1965-1973 гг., первое несоветское поколение 1974-1985 гг., цифровое поколение - 1986-2014 гг.

Исследование мотивации выбора профессии в юношестве у разных поколений было проведено с помощью методики «Мотивы выбора профессии» Овчаровой Р.В. для выявления внутренних индивидуально и социальнозначимых мотивов и внешних положительных и отрицательных мотивов, а также опросника Кибирева А.А. для выявления доминирующих мотивов выбора профессии. В исследовании принимали участие представители четырех поколений (140 человек): поколение перестройки 27 человек, первое несоветское поколение - 20 человек, старшее-цифровое поколение - 42 человека и младшеецифровое поколение - 51 человек. Результаты исследования представлены в таблице 1 .

Таблица 1.

Результаты исследования при помощи методики Овчаровой Р.В.

\begin{tabular}{|l|c|c|c|c|}
\hline \multirow{2}{*}{$\begin{array}{c}\text { Виды } \\
\text { мотивов }\end{array}$} & \multicolumn{4}{|c|}{ Поколения } \\
\cline { 2 - 5 } & $\begin{array}{c}\text { Поколение } \\
\text { перестройки }\end{array}$ & $\begin{array}{c}\text { Первое } \\
\text { несоветское }\end{array}$ & $\begin{array}{c}\text { Старшее- } \\
\text { цифровое }\end{array}$ & $\begin{array}{c}\text { Младшее- } \\
\text { цифровое }\end{array}$ \\
\hline ВИЗ & 85 & 85 & 71 & 75 \\
\hline ВС3 & 52 & 30 & 62 & 57 \\
\hline ВнешП & 11 & 15 & 14 & 25 \\
\hline Внеш0 & 11 & 5 & 19 & 4 \\
\hline
\end{tabular}

Внутренние индивидуально-значимые мотивы являются доминирующими у большинства представителей всех поколений: поколение перестройки и первое несоветское - 85\%, старшее-цифровое - 71\%, младшее-цифровое - 75\%. Это говорит о том, что большинство людей всех обследуемых поколений в юношеском возрасте опирались (опираются) на собственные желания, способности и задатки при выборе профессии.

Результаты исследования доминирующих мотивов выбора профессии представлены в виде двух таблиц: таблица 2 и таблица 3.

Таблица 2.

Результаты исследования мотивов выбора профессии по методике Кибирева А.А. В соотношении с внутренними мотивами по методике Овчаровой Р.В. (\%)

\begin{tabular}{|c|l|c|c|c|c|}
\hline \multicolumn{2}{|c|}{ Виды мотивации } & \multirow{2}{*}{$\begin{array}{c}\text { Поколение } \\
\text { перестройки }\end{array}$} & $\begin{array}{c}\text { Первое } \\
\text { несоветское }\end{array}$ & $\begin{array}{c}\text { Старшее } \\
\text { цифровое }\end{array}$ & $\begin{array}{c}\text { Младшее } \\
\text { цифровое }\end{array}$ \\
\hline \multirow{2}{*}{ Овчарова Р.В. } & \multicolumn{1}{|c|}{ Кибирев А.А. } & 89 & 95 & 86 & 100 \\
\hline \multirow{2}{*}{$\begin{array}{l}\text { Внутренние } \\
\text { мотивы }\end{array}$} & Свободный выбор & 67 & 55 & 31 & 16 \\
\cline { 2 - 4 } & Предметный выбор & 4 & 10 & 24 & 4 \\
\cline { 2 - 3 } & Компенсаторный выбор & & & \\
\hline
\end{tabular}


Результаты исследования мотивов выбора профессии по методике Кибирева А.А. в соотношении с внешними мотивами по методике Овчаровой Р.В. (\%)

\begin{tabular}{|c|c|c|c|c|c|}
\hline \multicolumn{2}{|r|}{ Виды мотивации } & \multirow{2}{*}{$\begin{array}{c}\text { Поколение } \\
\text { перестройки }\end{array}$} & \multirow{2}{*}{$\begin{array}{c}\text { Первое } \\
\text { несоветское }\end{array}$} & \multirow{2}{*}{$\begin{array}{l}\text { Старшее } \\
\text { цифровое }\end{array}$} & \multirow{2}{*}{$\begin{array}{l}\text { Младшее } \\
\text { цифровое }\end{array}$} \\
\hline Овчарова Р.В. & Кибирев А.А. & & & & \\
\hline \multirow{11}{*}{$\begin{array}{l}\text { Внешняя } \\
\text { мотивация }\end{array}$} & Родительский сценарий & 22 & 25 & 24 & 10 \\
\hline & Династический выбор & 15 & 10 & 5 & 2 \\
\hline & Родительское завещание & 7 & 5 & 7 & 2 \\
\hline & Консультационный выбор & 19 & 5 & 19 & 0 \\
\hline & Стадный выбор & 7 & 10 & 2 & 6 \\
\hline & Социально-инфраструктурный выбор & 11 & 20 & 14 & 24 \\
\hline & Ситуационно-прагматический выбор & 4 & 10 & 31 & 47 \\
\hline & Инфантильный выбор & 0 & 10 & 17 & 12 \\
\hline & Антипрофессия & 7 & 5 & 17 & 16 \\
\hline & Телевизионный фактор & 7 & 5 & 14 & 8 \\
\hline & Книжный фактор & 30 & 10 & 5 & 8 \\
\hline
\end{tabular}

Мотивация свободного выбора является доминирующим у большего количества представителей всех поколений, что говорит о восприятии выбора профессии как собственного, личностного выбора, который зависит только от собственных взглядов и умений. Предметный выбор предпочитают представители поколения перестройки (67 \%) и первого несоветского поколения (55\%), а компенсаторный выбор характерен в большей степени для старшего цифрового поколения (24 \%).

Анализируя результаты исследования внешних мотивов, необходимо отметить, что для поколения перестройки ведущим являются факторы книжного выбора, родительского сценария и консультативного выбора. Первое несоветское поколение схоже с поколением перестройки наличием родительского сценария, но отличаются социально-инфраструктурным выбором. Для старшего цифрового поколения также характерно наличие родительского сценария. От предыдущих поколений старшее цифровое поколение отличает приоритетный ситуационно-прагматический выбор. Данная характеристика в еще более выраженной степени присуща и последующему поколению младшему цифровому.
Результаты исследования мотивов выбора профессии и их анализ позволил сделать следующие выводы. В группе внутренних мотивов, доминирующих над внешними мотивами, наблюдается приоритет индивидуально-значимых мотивов над социально-значимыми. Мотивация свободного выбора является доминирующей у большего количества представителей всех поколений. Мотивация предметного выбора уменьшает свою значимость с течением смены поколений. Представители старшего-цифрового поколения в большей степени руководствовались компенсаторным выбором.

Внешние положительные мотивы в разной степени характерны всем поколениям. Большее значение в профессиональном выборе в группе внешних мотивов имеют родительский выбор для поколений перестройки, первого несоветского и старшего цифрового. Старшее цифровое поколение и поколение перестройки объединяет консультативный выбор. Социально-инфраструктурный выбор характерен в большей степени для первого несоветского и младшего цифрового поколений. А также интересными и логичными представляются результаты общего ситуационно-прагматического выбора старшего и младшего цифровых поколений.

\section{ЛИТЕРАТУРА}

1. Ильин Е.П. Мотивация и мотивы. - СПб.: Питер, 2011. - 512 с.

2. Кибирев А.А. Активные методы обучения и профконсультирования. Практикум по профориентации школьников старших классов: методические рекомендации. - Хабаровск: ХК ИППК ПК, 2005. - 75 с.

3. Кричевский Р.Л., Дубовская Е.М. Социальная психология малой группы: Учебное пособие для вузов. - М.: Аспект Пресс, 2001. - $318 c$.

4. Мирошкина М.Р. Интерпретации теории поколений в контексте российского образования // Ярославский педагогический вестник - 2017 - №6. - С. $30-35$.

5. Пряжников Н.С. Психологический смысл труда: Учебное пособие к курсу «Психология труда и инженерная психология» - М.: Издательство «Институт практической психологии», Воронеж: НПО «МОДЭК», 1997. - 352 с.

с Усольцева Виктория Владимировна (Vikitory@yandex.ru). 